\title{
Can Children with Intellectual Disabilities to be Taught to Protect to from Sexual Abuse?
}

\author{
Sibel Kucuk ${ }^{1}$ \\ Health Science Faculty, Ankara Yildirim Beyazit University, Turkey \\ *Corresponding author: Sibel Kucuk, PhD, Ankara Yildirim Beyazit University, Etlik Dogu Campus Keçiören, Ankara; Turkey \\ Submission: 漈 February 20, 2018; Published: 眥 May 08, 2018
}

\section{Introduction}

Sexual abuse is a common problem that can be seen in every part of society. Especially women and children are affected by sexual abuse. It is reported to mentally handicapped children who to be abused tend to be more than their healthy peers [1,2]. Sexual abuse can be for various reasons, such as increasing interest in sexuality with puberty [3], the events inability to express and evaluate, wants to benefit of abusers from the disadvantaged situations of intellectually disabled children $[4,5]$.

It is reports to, healthy child who were taught about from sexual abuse, were exposed abuse to in half less than those who didn't receive this education [6,7]. It is stated that it is important for children with mental disabilities as well as healthy children to take preventive education for abuse [8,9]. However, education on the prevention of sexual abuse of children with disabilities is often overlooked.

The training of children with mental retardation against sexual abuse is basically as follows; learning and body recognition of special body regions, good and bad touch, learning to say no, establishing a safe boundary with strangers, and reporting abuse [10].

It is reported that it is important for mentally retarded children to learn specific body regions [10] and that children who do not know the names of sexual regions are more abused [11]. The important point in learning about special body regions is learning the correct terminology and genital organ names correctly. This makes it easier for children to understand and report on touch when they are exposed to inappropriate touching behaviors [12]. It is known that mental retarded children's ability to name and display body parts is less than that of average intelligence children, and that these children are able to identify and display body regions at the rate of their vocabulary [13]. However, it has been reported that mentally retarded children can learn specific body regions with appropriate training [10]

Another step in sexual abuse prevention education is to learn good and bad touch, and to learn to say no [14]. It is reported to be healthy [15] and mentally retarded children an important step in the protection of sexual abuse [10]. As a result of the trainings given, it shows that the authority figures of mentally retarded children are conscious about different touches [10].

Learning to say no to unwanted activities reduces the likelihood of exploitation of children. It is known that children can learn to resist behavior such as reward, request, and praise from authority figures, making it easier for them to be protected from possible abuse [16].

Resistance to abuse is another way of saying no. However, 41.3$81.4 \%$ of children can not show any resistance to sexual assault $[4,17]$. However, it is stated in the prevention of child sexual abuse that it is important for children to resist inappropriate behavior and, if possible, to move away from the abuser [10].

Another step in prevention of abuse training is to establish security boundaries with strangers. Especially not talking to strangers and not giving out private information, establishing a safe boundary has an important place to protect from the abuses that foreigners have caused [16].

Repetition of exploitation may produce undesirable consequences. Therefore, it is important that the abuse should not be kept secret and reported to a reliable adult [17-19]. Mother is the most reliable family members to report abuse. Because almost all of the child sexual abusers are male, and all of the intrafamilial abusers are males [12].

It is known that children with mental disabilities are influenced by special education materials, repetitive, systematic, familysupported education is particularly effective in creating awareness of protection from sexual abuse in mildly mentally retarded children [10].

Mentally handicapped children are required to use materials that are appropriate for their intelligence and cognitive levels in their education. Trainings can be given with specially arranged pictures, stories, toys, etc. 
It should not be forgotten that mentally retarded children have a high likelihood of forgetting. Giving the trainings with a certain system and repetition reduces the possibility of forgetting children. It also increases the affectiveness of training.

Involvement and informing to education the parents of the education given to children with mental disabilities is important. Increasing the knowledge and awareness of family members about sexual abuse prevention can help increase the effectiveness of the training by moving it to the home environment.

\section{Conclusion}

Children with mental disabilities, like all children, need to be trained to prevent sexual abuse. These trainings can be enhanced by giving appropriate materials to children's intelligence levels and comprehension capacities, by regularly repeating the trainings, by ensuring the involvement of family members in the trainings and by moving the education to the home environment.

\section{References}

1. Skarbek D, Hahn K, Parrish P (2009) Stop sexual abuse in specia education: Anecological model of prevention and intervention strategies for sexual abuse in special education. Sexuality and Disabilities, 27(3): 155-164.

2. Lumley V A, Scotti JR (2001) Supporting the sexuality of adults with mental retardation: Current status and future directions. Journal of Positive Behavior Interventions 3(2): 109-119.

3. Akduman G, Ruban C, Akduman B, Korkusuz I (2006) Child and Sexual Exploitation. Forensic Psychiatry Journal 3 (1): 9-14.

4. Kucuk S (2016) Analyses of child sex abuse cases in turkey: A provincial case. J Child Sex Abus 25(3): 262-275.

5. Imren S, Ayaz AB, Yusufoglu C, Arman AR (2013) Clinical features and risk factors related with suicide attempts in sexually abused children and adolescents. Marmara Medical Journal 26: 11-16.

6. Gibson L, Leitenberg H (2000) Child sexual abuse prevention programs Do they decrease the occurrence of child sexual abuse? Child Abuse and Negl 24(9): 1115-1125.
7. Davis KM, Gidyez CA (2009) Child sexual abuse prevention programs: A metaanalysis. J Clin Child Psychol 29(2):257-65.

8. Topbas M (2004) A big shame of mankind: Child abuse. TAF Prev Med Bull 3(4): 76-80.

9. Cecen A R (2007) Child sexual abuse: Prevalence, effects and school based prevention. Journal of Human Sciences 1: 2-17.

10. Kucuk S, Platin N, Erdem E (2017) Increasing awareness of protection from sexual abuse in children with mild intellectual disabilities: An education study. Appl Nurs Res 38: 153-158.

11. Elliot M, Browne K, Kilcoyne J (1995) Child sexual abuse prevention: What offenders tell us. Child Abuse Negl 19(5): 579-594.

12. Boyle C, Lutzker J (2005) Teaching young children to discriminate abusive from nonabusive situations using multiple exemplars in a modified discrete trial teaching format. Journal of Family Violence 20(2): 55-69.

13. Simons J, Dedroog I (2009) Body awareness in children with mental retardation. Research in Developmental Disabilities 30: 1343-1353.

14. Topping KJ, Barron IG (2009) School-based child sexual abuse prevention programs: A review of effectiveness. Review of Educational Research 79(1): 431-463.

15. Hayward S, Pehrsson DE (2000) Interdisciplinary action supporting sexual assault prevention efforts in rural elementary schools. Journal of Community Health Nursing 17(3): 141-150.

16. Fisher LG, Jenkins SJ, Bancroft MJ (1985) Teaching the mentally handicapped to avoid sexual exploitations. Nevada: College of Education, University of Nevada.

17. Golge BZ, Yavuz MF, Yuksel S (2006) Sexual assailants' profiles. Journal of Forensic Medicine, 20(1): 1-17.

18. Davis LA (2002) People with cognitive, intellectual and developmental disabilities \& sexual offenses (Q \&a). The arc 1-2: 150.

19. Glaser D (2002) Child sexual abuse. In: M Rutter \& Taylor T (Eds.), Child and adolescent psychiatry. Massaachusetts, US: Blackwell Publishing Company, pp. 340-358.
Creative Commons Attribution 4.0

International License

For possible submissions Click Here

\section{Submit Article}

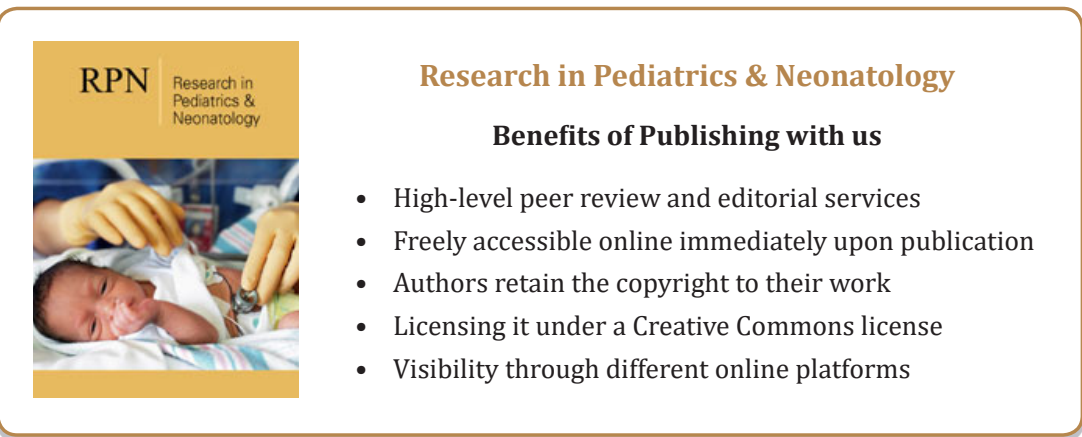

